\title{
CARDIOTOXIC EFFECT DUE TO ACCIDENTAL INGESTION OF AN ORGANIC SOLVENT
}

\section{URSZULA IZABELA CIEŚLIK-GUERRA ${ }^{1}$, TOMASZ RECHCIŃSKI ${ }^{1}$, EWA TRZOS ${ }^{1}$, KARINA WIERZBOWSKA-DRABIK ${ }^{1}$, BARBARA UZNAŃSKA-LOCH ${ }^{1}$, RENATA WINNICKA ${ }^{2}$, ANNA KRAKOWIAK ${ }^{3}$, JAROSŁAW DAMIAN KASPRZAK ${ }^{1}$, COLIN FRÖHLICH ${ }^{4}$, and MALGORZATA KURPESA ${ }^{1}$}

${ }^{1}$ Medical University of Lodz, Łódź, Poland

Chair and Department of Cardiology, Bieganski Hospital

${ }^{2}$ Nofer Institute of Occupational Medicine, Łódź Poland

Toxicological Laboratory

${ }^{3}$ Nofer Institute of Occupational Medicine, Łódź, Poland

Toxicology Unit

${ }^{4}$ Medical University of Lodz, Łódź, Poland

Faculty of Medicine with the Division of Dentistry

\begin{abstract}
Toxic myocardial injury can be misdiagnosed as a myocardial infarction, resulting in the patient undergoing standard treatment for cardiac rehabilitation. However, such inadequate therapeutic strategies can lead to cardiovascular complications including dilated cardiomyopathy. This study presents a case of a 65-year-old man after accidental ingestion of organic solvents (toluene and xylene), whose condition demonstrated all the criteria for diagnosis of myocardial infarction. The qualitative determinations of the above mentioned volatile organic compounds (VOCs) in whole blood were carried out using a headspace sampling by means of gas chromatography. Cardiac catheterization revealed no specific coronary lesions, only a muscular bridge causing a 30-50\% stenosis in the middle of the circumflex branch of the left coronary artery.
\end{abstract}

Key words:

Miocardial infarction, Cardiotoxicity, Xylene, Poisoning, Volatile organic compounds, Toluene

\section{INTRODUCTION}

Work conditions may at times promote intoxication that could result in cardiotoxicity. Cardiotoxic agents, including volatile organic compounds (VOCs), such as organic solvents e.g., toluene and xylene, have been reported to cause various cardiac effects, however, myocardial infarction is rarely reported [1]. They affect tissues rich in lipids, leading to their peroxidation and causing the release of toxic free radicals. The resulting oxidative stress causes congestion, inflammation, increase in apoptosis in the tissue as well as vasospasm [2]. The above mentioned VOCs target the cardiovascular system as well as the nervous, musculoskeletal, excretory, respiratory and other systems and organs.

Acute ingestion can cause damage to the heart before the defense mechanisms are activated. While chest pain is

Received: July 8, 2014. Accepted: October 22, 2014.

Urszula Izabela Cieślik-Guerra and Tomasz Rechciński contributed equally to this work and should be both considered as 1st authors.

Corresponding author: U.I. Cieślik-Guerra, Medical University of Lodz, Chair and Department of Cardiology, Bieganski Hospital, Kniaziewicza 1/5, 91-347 Łódź, Poland (e-mail: cieursz@wp.pl). 
a very common complaint in emergency cardiology, a concomitant increase of troponin in such a situation suggests the differential diagnosis of myocardial infarction. Lack of adequate therapeutic strategies at this stage and following standard guidelines can result in further cardiovascular complications.

The present case study presents a patient experiencing a toxic myocardial injury after accidental ingestion of an organic solvent. The early initiation of an exercise program of cardiac rehabilitation in such a patient may result in further progression of a myocardial damage, rather than the expected improvement.

\section{CASE DESCRIPTION}

A 65 -year-old farmer was transported by an ambulance to the Toxicology Unit, The Nofer Institute of Occupational Medicine in Łódź after accidental consumption of an organic solvent of an unknown composition. On a hot day, the farmer was working in the garage and, by mistake, drank about $150 \mathrm{ml}$ of an organic solvent, which had been kept in a colored bottle originally used for a carbonated beverage. The patient was a smoker but denied regular alcohol consumption and addiction to any organic solvents. He had previously been diagnosed with arterial hypertension and Prinzmetal angina but was not receiving any regular medications. The 1st symptoms after consumption were: tiredness, confusion, weakness, drunken-like actions, nausea, abdominal pain, vomiting and diarrhea. Crushing pain in the chest appeared after $40 \mathrm{~min}$. General condition of the patient was serious and logical contact was difficult. The odor of gasoline was perceptible around the patient. The patient had a slim build (body mass index - 20.5).

Clinical examination showed an oxygen saturation of $95 \%$ room air, a respiratory rate of 20 breaths per min, blood pressure of $140 / 80 \mathrm{~mm} \mathrm{Hg}$ and heart rate of 80 beats per min. No changes were seen in the meninges or the focal lengths of the central nervous system. The patient also did not develop pulmonary toxicity after solvent ingestion. The pupils were wide, with a normal reaction to light. Blood tests revealed a slightly elevated white cell count of $10.1 \times 10^{9} / 1$ (normal range: $\left.4-10 \times 10^{9} / 1\right)$, mild anemia - red cell count $-4.05 \times 10^{6} / 1$ (normal range: $\left.4.5-6.0 \times 10^{6} / 1\right)$, hemoglobin $-12.2 \mathrm{mg} / \mathrm{dl}$ (normal range: $13.5-18 \mathrm{mg} / \mathrm{dl}$ ), hematocrit $-37.1 \%$ (normal range: $42-55 \%$ ), thrombocytopenia - $103 \times 10^{3} / 1$ (normal range: $\left.150-400 \times 10^{3} / 1\right)$, a raised creatine kinase $(\mathrm{CK})$ activation of $223 \mathrm{U} / 1$ (normal range: < $170 \mathrm{U} / \mathrm{l}$ ), creatine kinase mass isoenzyme MB (CK-MB) of $20.89 \mathrm{ng} / \mathrm{ml}$ (normal range: $0-6.76 \mathrm{ng} / \mathrm{ml}$ ), highly sensitive troponin $\mathrm{T}\left(\right.$ Trop $\mathrm{T}_{\mathrm{hs}}$ ) of $0.238 \mathrm{ng} / \mathrm{ml}$ (normal range: $<0.1 \mathrm{ng} / \mathrm{ml}$ ).

Toxicological analysis of the patient's blood samples indicated the presence of toluene and mixture of xylene isomers. The qualitative determinations of volatile organic compounds in the whole blood were carried out using a headspace sampling with a gas chromatograph (HS-GC) Hewlett Packard 6890, coupled with an analytic computer station "HP ChemStation" and equipped with Flame Ionization Detector - FID, and capillary column HP-5: length - $30 \mathrm{~m}$, inside diameter $-0.53 \mathrm{~mm}$, film thickness $-2.65 \mu \mathrm{m}$, split inlet. The analysis included identification of 28 volatile organic compounds but did not obtain complete separation of xylene isomers: o-xylene was identified separately and m-xylene and p-xylene were identified together. Toxicological examination of the whole blood collected on the poisoning day did not detect any ethanol. The blood ethyl and methyl alcohol levels were determined using a gas chromatograph SRI 310C, equipped with FID detector and column $(2 \mathrm{~m} \times 2 \mathrm{~mm})$ packed with Tenax 60/80 mesh.

The patient received an easily digestible, fat-free diet and oral irrigation. His physical activity was reduced and intravenous infusion of crystalloids was performed. Based on the elevated markers of myocardial necrosis (CK-MB mass $-64.37 \mathrm{ng} / \mathrm{ml}$, Trop $\mathrm{T}_{\mathrm{hs}}-1.98 \mathrm{ng} / \mathrm{ml}$ ), the patient was referred to the Department of Cardiology. After the transfer the patient was in a stable condition. 

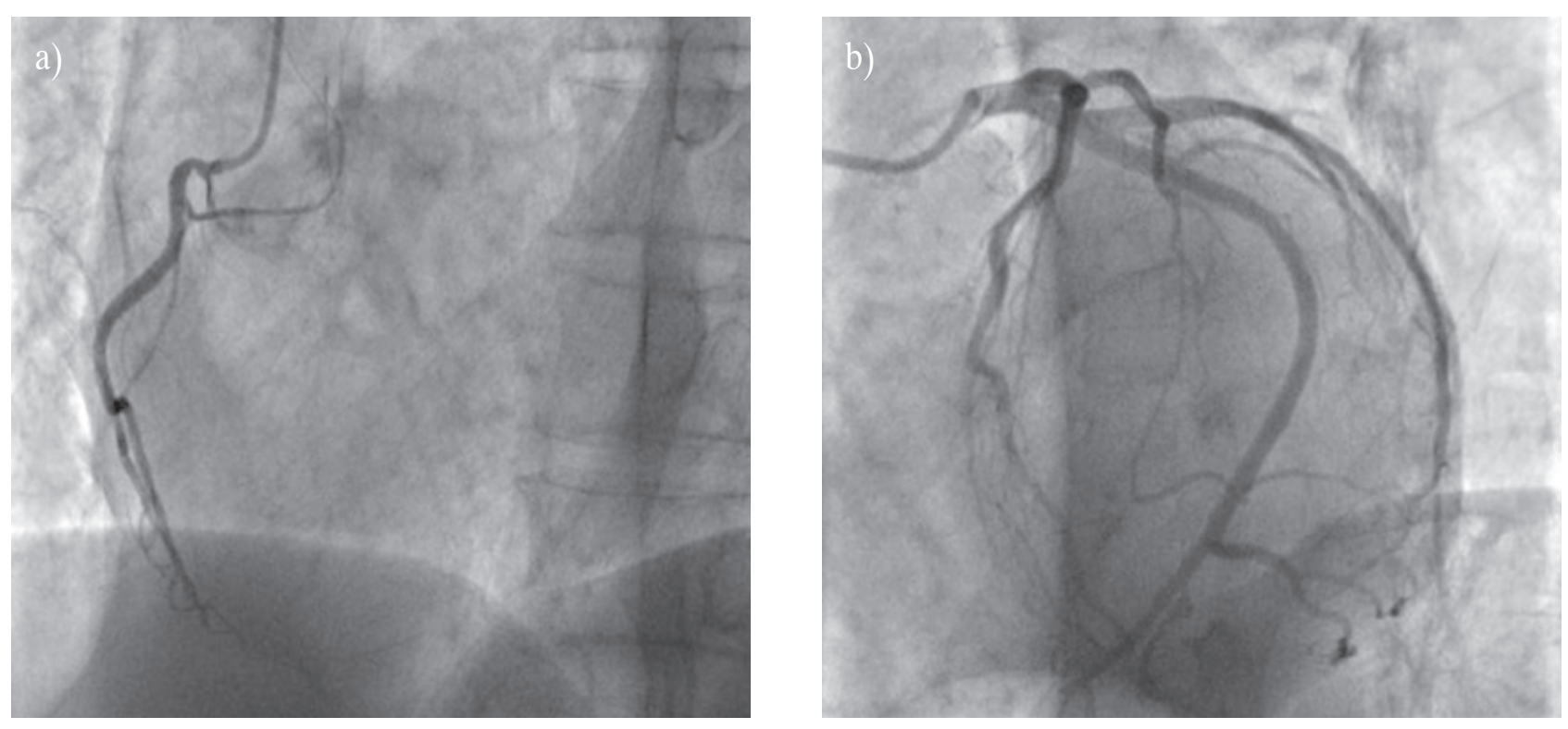

a) right coronary artery (LAO 50.30; CAU 0.40), b) left coronary artery (LAO 30.40; CAU 20.40).

Photo 1. Coronary angiography shows no significant coronary lesions

An echo scan showed hypokinesia within the apical segments of the lateral, posterior, anterior and inferior walls, and an ejection fraction of $38 \%$. Angiography revealed marginal changes in the coronary arteries, with a muscular bridge causing $30-50 \%$ stenosis in the middle of the circumflex branch of the left coronary artery (Photo 1).

a)

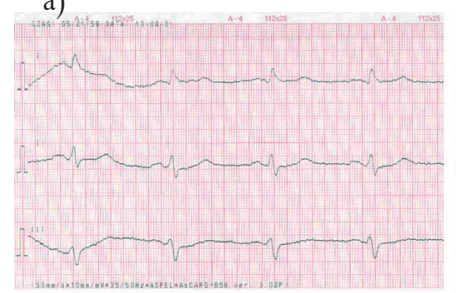

b)

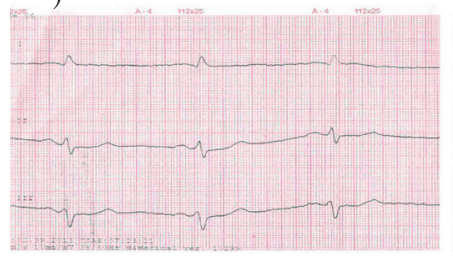

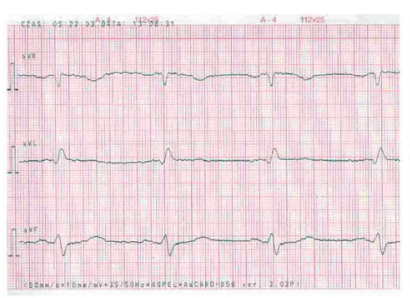

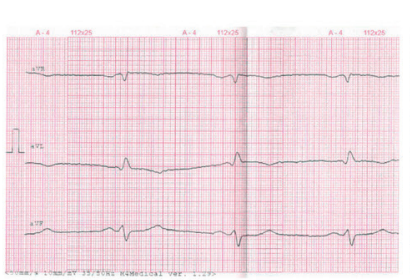

During 4 days of hospitalization in the Department of Cardiology, the myocardial necrosis markers gradually subsided: CK-MB mass - $7.59 \mathrm{ng} / \mathrm{ml}$, Trop $\mathrm{T}_{\mathrm{hs}}-0.522 \mathrm{ng} / \mathrm{ml}$. A negative T wave in aVL, V4-V6 was seen on an electrocardiography (ECG) taken on the 2nd day after admission without any changes till discharge (Photo 2). The patient,

a) upper panel shows ECG at admission, b) lower panel shows ECG at the 2nd day of hospitalization which remained unchanged to the time of discharge - negative T wave in aVL, V4-V5 were present.

Photo 2. Twelve-lead electrocardiography (ECG) 
in good condition and without symptoms, was discharged for further ambulatory observation and no exercise program was recommended for the purpose of early cardiac rehabilitation.

\section{DISCUSSION}

Toluene and xylene are clear, water-insoluble aromatic hydrocarbons commonly used in industry, which are mainly produced by refining petroleum. Addiction to inhalation of organic solvents is a major problem in many countries, however, frequent accidental intoxication, especially by inhalation, but also by ingestion, can also occur. Organic solvents are lipophilic and have affinity for the nervous system, kidneys, liver, lung and heart. Toluene has been recently observed to have acute cardiotoxic effects when administered orally to rats [2]. Histopathological examination of the heart tissue section revealed edema and congestion. In the hearts of rats exposed to toluene significantly higher numbers of apoptotic cells were observed.

After intoxication, the blood pressure and heart rate of the animals were significantly lower and the median Trop $\mathrm{T}$ levels were 14 times higher than those of the control group. Heart tissue damage, vasospasm, endothelial dysfunction and hypokalemia are mechanisms suspected to be responsible for symptoms of a toxic myocardial injury [2,3].

According to the 3rd and current universal definition, a diagnosis of myocardial infarction should be considered if cardiac biomarkers (preferably troponin) are above the 99th percentile of the upper reference limit and one of the following criteria is also fulfilled: symptoms of ischemia, specific changes in ECG, imaging evidence of myocardium changes or indication of intracoronary thrombus [4]. All of the above mentioned criteria were present in the described patient. Toxic myocardial injury may be easily confused with an acute myocardial infarction. Following an acute coronary syndrome, a typical patient requires rescue reperfusion, pharmacotherapy and early complex cardiac rehabilitation. However, the patient in the present study required a unique therapeutic strategy, which not only didn't include reperfusion therapy, but also included a recommendation to avoid physical exertion contraindicated after toxic cardiac damage.

The patients described in previous studies of this type are typically younger and are usually addicted to sniffing organic solvents [5,6]. Hussain et al. have reported the case of a 55-year-old man who was admitted to hospital 11 times over 18-month period due to a toluene-related recurrent non-Q-wave myocardial infarction [5]. The patient was addicted to inhaling toluene 24 years before the 1 st admission to hospital. He underwent 3 catheterizations, revealing normal coronary arteries [5]. Cunningham et al. reports a case of a 16-year-old boy with a history of heavy solvent abuse - of unknown duration - who suffered from an anterior myocardial infarction complicated by cardiac arrest via a mechanism of ventricular fibrillation [6]. Information suggesting that cardiac rehabilitation or any physical exertion at all should be avoided early after intoxication is missing in all the available case reports describing similar cases.

Vasospasm caused by increased sensitivity to catecholamines is one of the postulated mechanism responsible for symptoms of a toxic myocardial injury [2,5,6]. Our patient had a medical history of Prinzmetal angina, which was successfully treated with calcium channel blockers. It is possible that the vasospasm initiated a cardiotoxic reaction but typical ST segment elevation was not registered on the ECG.

Precise time duration of the toxic effects of organic solvents on the heart is not available in the literature. However, recent reports note that, apart from a myocardial injury, a wide range of other consequences of heart damage exist, such as: arrhythmia, atrioventricular conduction abnormalities, dilated cardiomyopathy, sudden cardiac death and myocarditis [7-12]. Our patient had an ejection fraction reduced to $38 \%$. We suspected that in this 
case it was rather an acute reaction to intoxication. But there are descriptions of dilated cardiomyopathy caused by chronic abuse of organic solvents. Vural et al. have presented a case of a 21-year-old man who inhaled volatile substances for more than 10 years before dilated cardiomyopathy was diagnosed [7]. The patient was followed up 6 months after he stopped inhaling volatile substances. Control echocardiography revealed an ejection fraction improvement from 40 to $55 \%$ [7].

Lisowska et al. have recorded an increase of ejection fraction from 15 to $45 \%$ in a 26 -year-old patient after standard pharmacotherapy [8]. Wiseman et al. reports a case of a 15-year-old boy addicted to sniffing glue, the main component of which is toluene [9]. The patient started with an ejection fraction of $17 \%$ and after failure in the treatment using pharmacotherapy, required a heart transplantation. Histological appearance of the excised heart revealed nonspecific myocarditis [9]. Myocardial injury and dilated cardiomyopathy can lead to different kinds of arrhythmia such as atrial fibrillation and ventricular fibrillation [6,8]. Cruz et al. have suggested that not only myocardium sensitization to endogenous catecholamines could be responsible for arrhythmogenic effect but inhibition of cardiac sodium channels as well [10]. This last mechanism is highly probable to be involved in a sudden cardiac death [11].

It is important to ascertain what solvent was ingested as this can aid medical personnel to determine a proper treatment strategy. In this case, it was not warranted to induce vomiting as this might have led to pulmonary aspiration further complicating the patient's delicate state [13].

\section{CONCLUSIONS}

This case highlights the importance of a toxicological interview with a patient suffering from a suspected myocardial infarction. This knowledge helps to provide an adequate treatment without early cardiac rehabilitation, which, as in the case described above, could lead to a further cardiac damage and dilated cardiomyopathy.
An additional message from this case concerns application of principles of safety in occupational health also in farms. Properly labeled bottles as well as avoidance of reusing bottles for personal consumption could prevent a farmer from poisoning himself.

\section{REFERENCES}

1. Gummin DD. Hydrocarbons. In: Nelson LS, Lewin AN, Howland MA, Hoffman RS, Goldfrank LR, Flomenbaum NE, editors. Goldfrank's toxicologic emergiencies. New York: The MacGraw-Hill Company; 2011. p. 1386-99.

2. Taş U, Ekici F, Koç F, Söğüt E, Ayan M, Kuloğlu T, et al. Acute cardiotoxic effects of high dose toluene: An experimental study. Anadolu Kardiyol Derg. 2013;13:3-8.

3. Baskerville JR, Tichenor GA, Rosen PB. Toluene induced hypokalaemia: Case report and literature review. Emerg Med J. 2001;18:514-6, http://dx.doi.org/10.1136/ emj.18.6.514.

4. Thygesen K, Alpert JS, Jaffe AS, Simoons ML, Chaitman BR, White HD. Joint ESC/ACCF/AHA/WHF task force for universal definition of myocardial infarction. Third universal definition of myocardial infarction. J Am Coll Cardiol. 2012;60:1581-98, http://dx.doi.org/10.1016/ j.jacc.2012.08.001.

5. Hussain TF, Heidenreich PA, Benowitz N. Recurrent nonQ-wave myocardial infarction associated with toluene abuse. Am Heart J. 1996;131:615-6, http://dx.doi.org/10.1016/S00 02-8703(96)90549-9.

6. Cunningham SR, Dalzell GW, McGirr P, Khan MM. Myocardial infarction and primary ventricular fibrillation after glue sniffing. BMJ (Clin Res Ed). 1987;294:739-40, http://dx. doi.org/10.1136/bmj.294.6574.739-a.

7. Vural M, Ogel K. Dilated cardiomyopathy associated with toluene abuse. Cardiology. 2006;105:158-61, http://dx.doi. org/10.1159/000091344.

8. Lisowska A, Skibinska E, Musial WJ. [Severe heart failure due to toxic cardiomyopathy in a young patient - A case report]. Kardiol Pol. 2004;60:372-3. Polish. 
9. Wiseman MN, Banim S. "Glue sniffer's" heart? Br Med J (Clin Res Ed). 1987;294:739, http://dx.doi.org/10.1136/ bmj.294.6574.739.

10. Cruz SL, Orta-Salazar G, Gauthereau MY, Millan-Perez Peña L, Salinas-Stefanón EM. Inhibition of cardiac sodium currents by toluene exposure. Br J Pharmacol. 2003;140: 653-60, http://dx.doi.org/10.1038/sj.bjp.0705481.

11. Prayulsatien W. Sudden death from toluene intoxication: A case report and review of literature. J Med Assoc Thai. 2013;96:1242-4.
12. Tsao JH, Hu YH, How CK, Chern CH, Hung-Tsang Yen D, Huang CI. Atrioventricular conduction abnormality and hyperchloremic metabolic acidosis in toluene sniffing. J Formos Med Assoc. 2011;110:652-4, http://dx.doi.org/ 10.1016/j.jfma.2011.08.008.

13. Kandyala R, Raghavendra SP, Rajasekharan ST. Xylene: An overview of its health hazards and preventive measures. J Oral Maxillofac Pathol. 2010;14:1-5, http://dx.doi. org/10.4103/0973-029X.64299.

This work is available in Open Access model and licensed under a Creative Commons Attribution-NonCommercial 3.0 Poland License - http://creativecommons.org/ licenses/by-nc/3.0/pl/deed.en. 